\title{
USING KINEMATIC ANALYSIS TO DEVELOP A NEW TOOTH SYSTEM FOR GEARINGS WITH VARIABLE SHAFT ANGLE
}

\author{
M. Grafinger $\bowtie$ \\ TU Wien, Austria \\ $\triangle$ manfred.grafinger@tuwien.ac.at
}

\begin{abstract}
The belt units of an omnidirectional treadmill need to be connected for a continuous rotational transmission with variating axes angle. Torus gearing is not appropriate due to kinematic reasons, therefore a crown gearing with cone-shaped teeth is proposed. Parameter analysis on a virtual kinematics model show that depending on the cone angle, overlaps occur at different axis angles. Consequently, the shape of the teeth is modified with tip and foot relief and optimized so that no overlapping of the teeth occurs while a large path of contact is provided.
\end{abstract}

Keywords: virtual engineering (VE), kinematic analysis, gearing systems, design evaluation, new product development

\section{Introduction}

For the development of an omnidirectional treadmill, patented by Rudelstorfer (2018), a tooth system is needed, that can transfer continuous rotation while variable angle of rotation axes occurs to ensure that the revolving belt units thread in correctly into the driving gear shaft (Figure 1). The necessary span of angle is from $0^{\circ}$ to $60^{\circ}$. Flexible shaft couplings could also be an alternative but they do not meet the requirements of large angle deviation and the given space requirements and so they are not considered further.

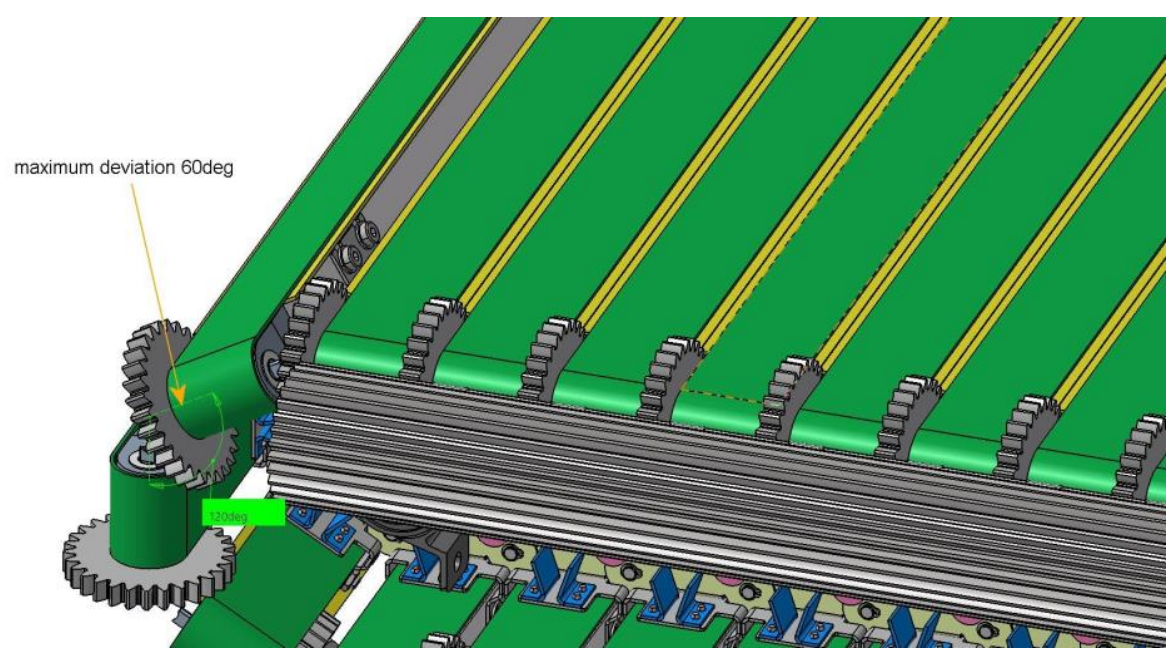

Figure 1. Revolving belt units of an omnidirectional treadmill (Rudelstorfer, 2018) 


\section{State of the art}

\subsection{Gears with variable axis angles}

Basstein and Sijtstra (1993) show that with computer calculation technologies the very old known crown gear system can be redesigned for various application fields and different axis angle (Figure 2). The pinion can always be the same evolvent shape with different crown wheels. The big advantage against bevel gears is the free axial position of the pinion. Crown gears can be designed for any axis angle but are not applicable for variable angle.

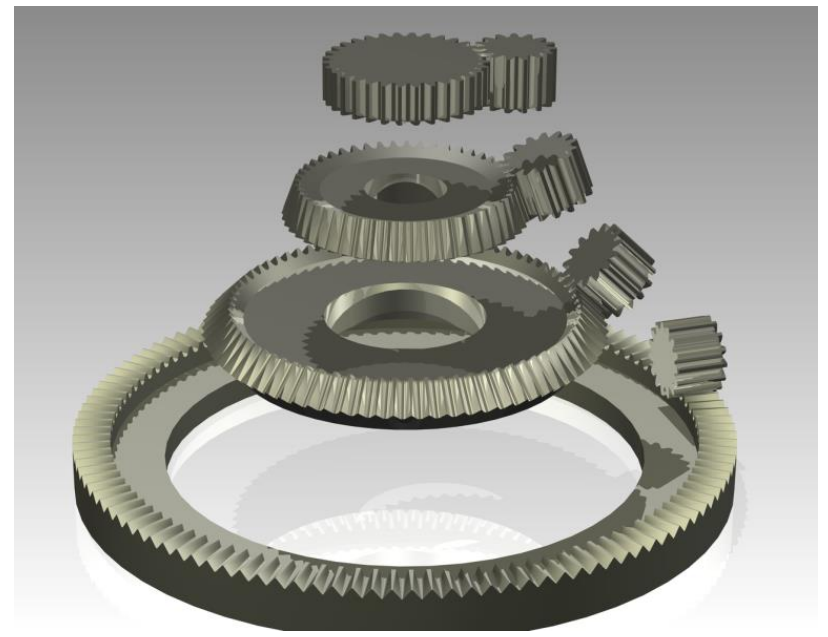

Figure 2. Crown gears with different axis angles (Hayoz, 2015)

Tsai (1997) developed a standardized set of equations for calculating evolvent based gearing systems like cylindrical, bevel, crown and torus gears. With those equations, based on general gearing theory, a geometric layout of torus gears became possible.

Roth (1998) recommends the torus gearing for variable shaft angle application. The drawback is the change of velocity pole and point of contact during shaft angle variation. This comes from the distance between centres of rotation according $\Phi_{\mathrm{T}}$ (Figure 3).
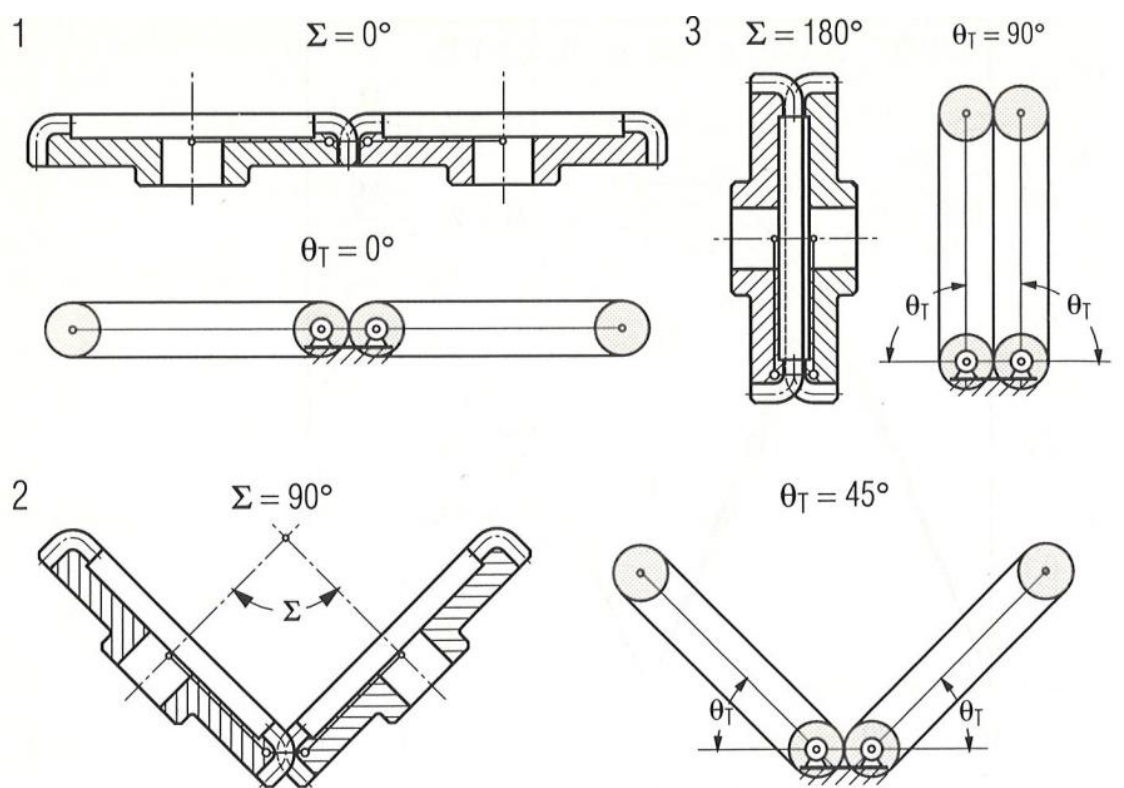

$$
\theta_{\top}=45^{\circ}
$$

Figure 3. Torus gear (Roth, 1998)

Another drawback of torus gear is the required space for the teeth on the outer cylinder barrel. In the application of the treadmill the driving gear is suited at this location (Figure 1). Therefore the 
development of a new toothing system with a constant point of contact inside the wheels cylinder barrel was necessary.

Out of the researched tooth systems the crowned gears seem to fit best the above discussed requirements. Since standard crown gears are also designed for constant angle of rotation axis, the tooth form has to be modified and optimized within a parametric virtual kinematic prototype.

\subsection{Parametric tooth mesh design optimization}

Common optimization strategies for finding local and global parameter optimized solutions are well described in Burkard and Zimmermann (2012). Philipp (2014) uses these algorithms for numerical optimization of generally used tooth geometry. Seol and Kim (1998) investigated the contact pattern of crown gears to recommend the appropriate amount of crowning under dynamic load. They developed a computer program to simulate the meshing of the crowned spur gears. Li et al. (2014) developed a mathematical model of the spherical involute tooth surface of a spiral bevel gear for numerical tooth contact analysis.

The literature found in the research deals with numeric simulation of special tooth contact problems but all of them need huge resources in mathematical modelling of the geometric problem. To spare these resources therefore this project takes another approach and simulates the tooth contact geometry with the kinematic simulation tool of a CAD - System. The base geometry of the gearing system for the omnidirectional treadmill was modelled in CATIA V5 and so the Digital Mockup (DMU) workbench inside CATIA was used for building the kinematic model. Behnisch (2003) describes the methodology how to create a kinematic analysis in CATIA V5.

\section{Parametric gear model}

\subsection{Parameter study on coned crown gears}

For validation of the usability of the crown gear over a wide range of variable axis angle a kinematic tooth system was built up in a parametric CAD model. In the first version coned crowns with constant cone angle were used. Cone angle and axis angle were defined as parameters for investigation of parameter variations (Figure 4).

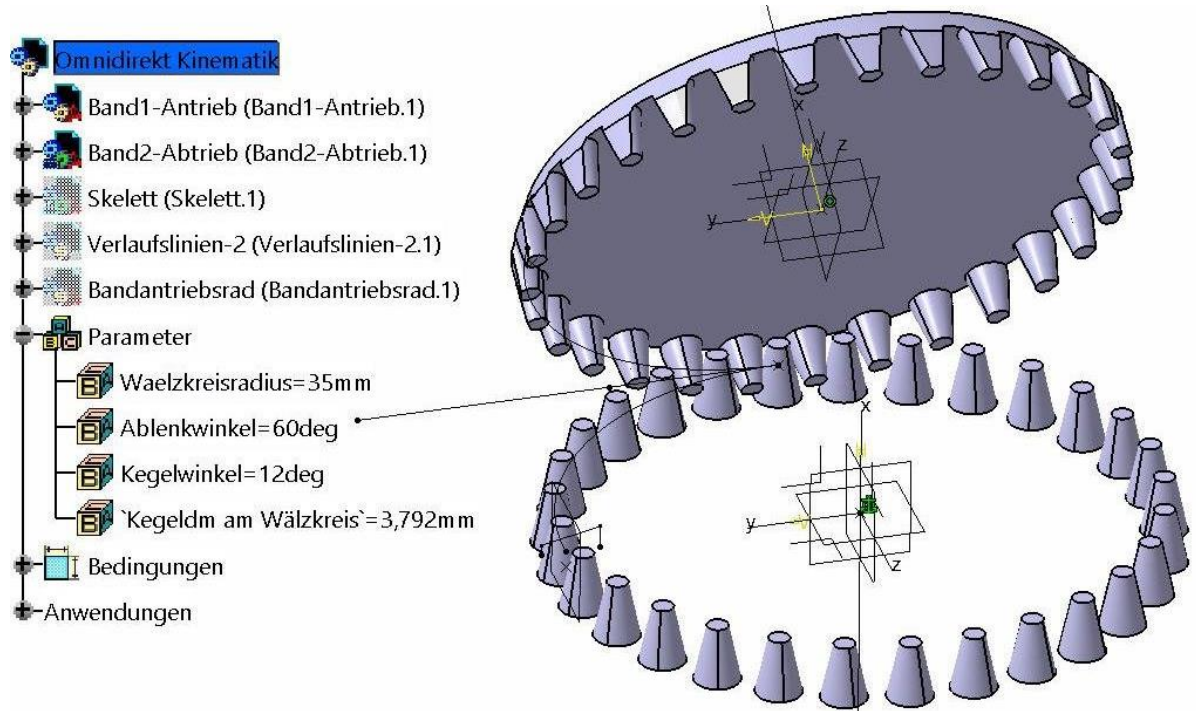

Figure 4. Parameter driven kinematic model in CATIA V5

Cone angles from $9^{\circ}$ to $25^{\circ}$ were investigated and for each of them the axis angle was varied from $0^{\circ}$ to $60^{\circ}$ for the needs of application. It came out that no configuration without collision of the cones while rolling over the teeth can be found. Figure 5 shows the needed space for the driven wheel while rolling over the drive wheel and Figure 6 shows an example for collision analysis in CAD model. Table 1 gives the overlapping depth at investigated combinations of cone angles and axis angles. 


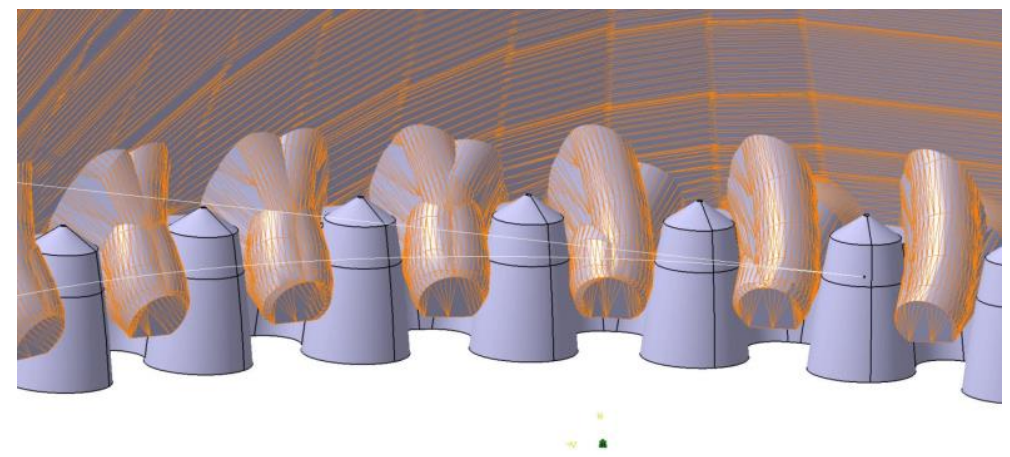

Figure 5. Swept volume of driven wheel over drive wheel

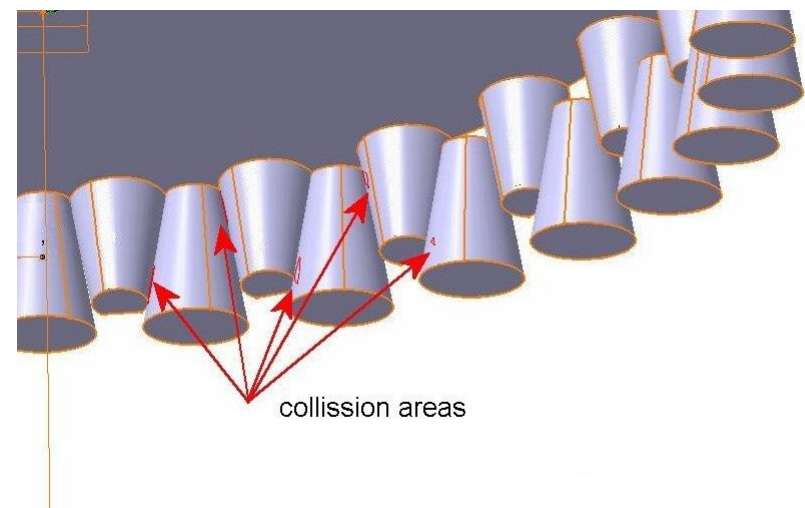

Figure 6. Example of collision analyses for $10^{\circ}$ cone angle at $10^{\circ}$ axis angle

Table 1. Depth of overlapping at different angle combinations

\begin{tabular}{rr|rrrrrrr}
\multicolumn{2}{r}{ Cone angle } & $9^{\circ}$ & $10^{\circ}$ & $12^{\circ}$ & $15^{\circ}$ & $18^{\circ}$ & $21^{\circ}$ & $25^{\circ}$ \\
\hline Axis angle & 5 & 0,11 & 0,08 & 0,06 & 0,01 & 0,01 & 0 & 0 \\
10 & 0,33 & 0,25 & 0,13 & 0,05 & 0,01 & 0 & 0 \\
15 & 0,31 & 0,29 & 0,14 & 0,04 & 0 & 0 & 0 \\
20 & 0,34 & 0,23 & 0,05 & 0 & 0 & 0 & 0 \\
40 & 0 & 0 & 0 & 0 & 0 & 0 & 0 \\
50 & 0 & 0 & 0 & 0 & 0 & 0,02 & 0,06 \\
55 & 0 & 0 & 0 & 0 & 0,01 & 0,04 & 0,09 \\
60 & 0 & 0 & 0 & 0 & 0,04 & 0,07 & 0,13
\end{tabular}

Best choose seems to be cone angles between $15^{\circ}$ and $20^{\circ}$ but these are also not applicable over the full range of needed axis angle. Because of the impossibility of a collision free transmission with simple coned crown gears in next step a tooth head relief is proposed to get a spherical shape in head area.

\subsection{Optimization with spherical shaped crown gears}

To eliminate the collisions an increasing head relief from pitch circle to tooth head for both tooth gears can be promissory. For parameter variation in the kinematic model the reached cone angle or the cone diameter on tooth head can be applicable.

One of the gear wheels will be manufactured of aluminium, while the other gear wheel will be made of carbon fibre reinforced plastic with FDM 3D printing. For the ease of milling the aluminium wheel keeps the constant cone angle and the CRP wheel gets the spherical tooth relief. The new tooth form now consists of a circular arc with 3 tangents, one with the angle at tooth feet, one at the pitch circle and one at tooth head (Figure 7). These angles are included in the parameter set of the kinematic model. 

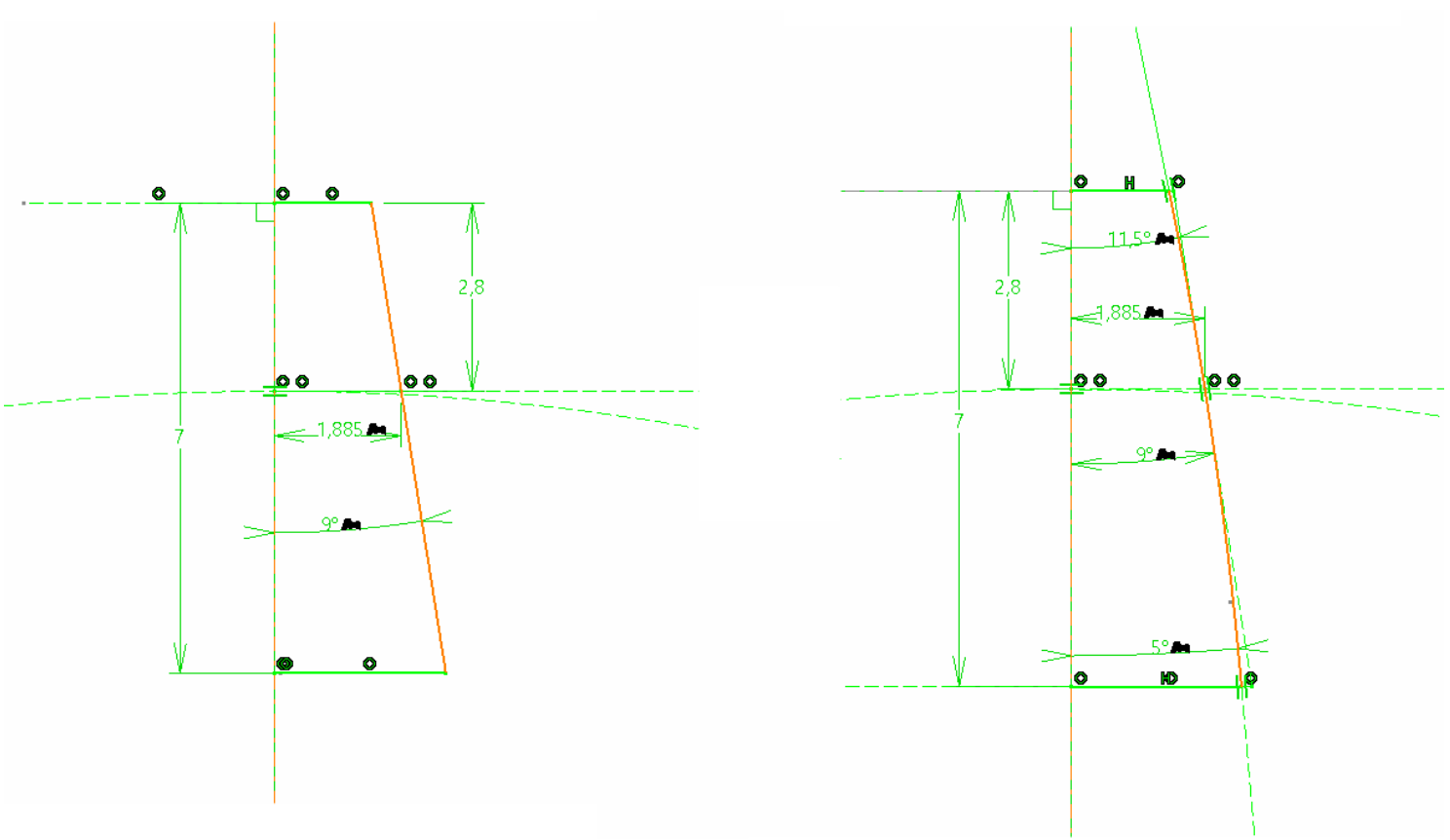

Figure 7. Geometry of crown tooth in first version (left) and new version (right)

The parameter for cone angle on milled wheel and tangent angle at pitch circle on printed wheel is determined to $9^{\circ}$ because at large angles the gaps between tooth feet get to small for manufacturing by milling cutter at configuration of 30 teeth and pitch radius of $36 \mathrm{~mm}$.

Parameter variation of foot angle and head angle was investigated with the result that about $2^{\circ}$ angle deviation from tangent angle at pitch curve are necessary at foot and head relief to avoid collision for axis angle from $0^{\circ}$ up to $60^{\circ}$. With this parameter set of $7^{\circ} / 9^{\circ} / 11^{\circ}$ cone angles from foot to head the final shape was determined.
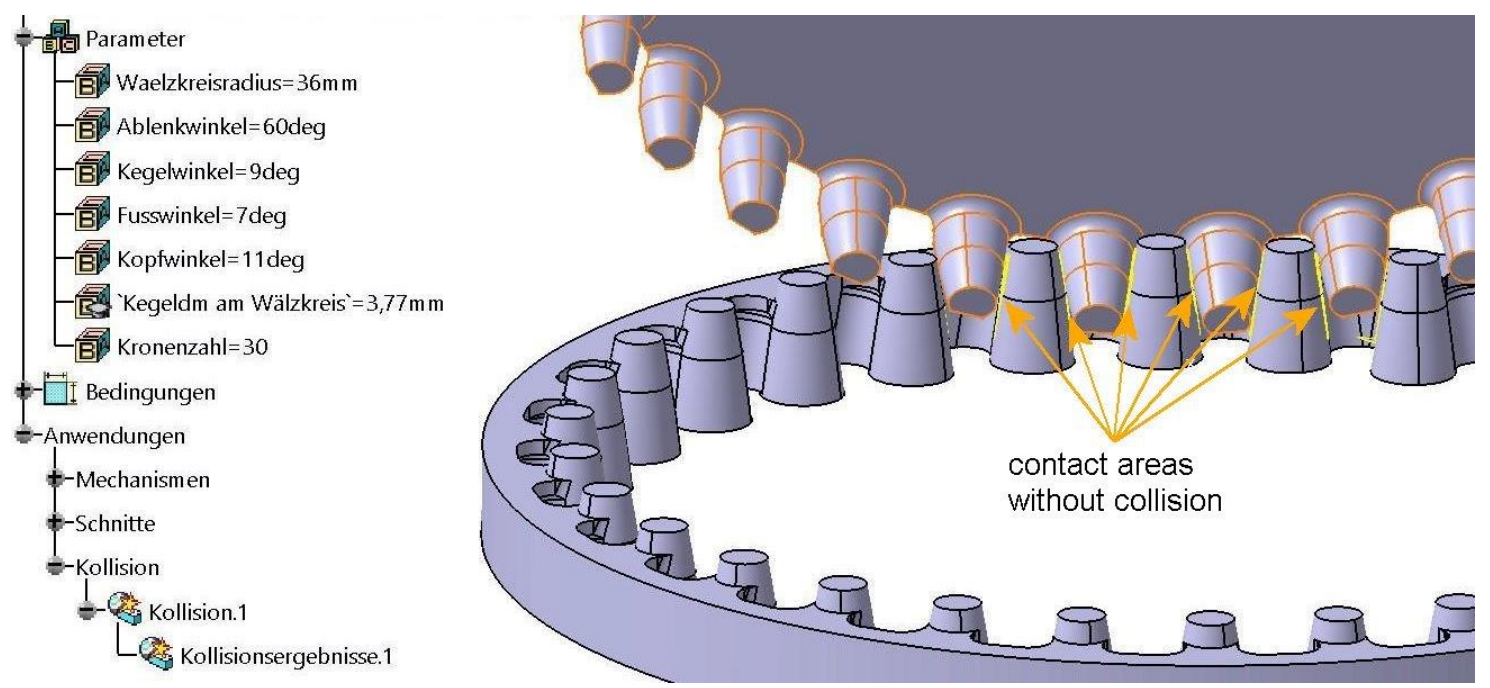

Figure 8. Parameter set for collision free transmission

\section{Validation on prototype}

To validate the new developed tooth system for the application of variable axis angle a test bench was built. Driving wheel is 3D printed of carbon fibre reinforced polyamide with the defined parameter set; the driven wheel is milled with constant cone angle of $9^{\circ}$. A stepper motor on the fixed part drives the test gears over a standard involute gear that later also should be applied in the omnidirectional treadmill. The movable part is connected with a pivot joint and is swivelled by a spindle drive to variate the axis angle during rotation (Figure 9). 


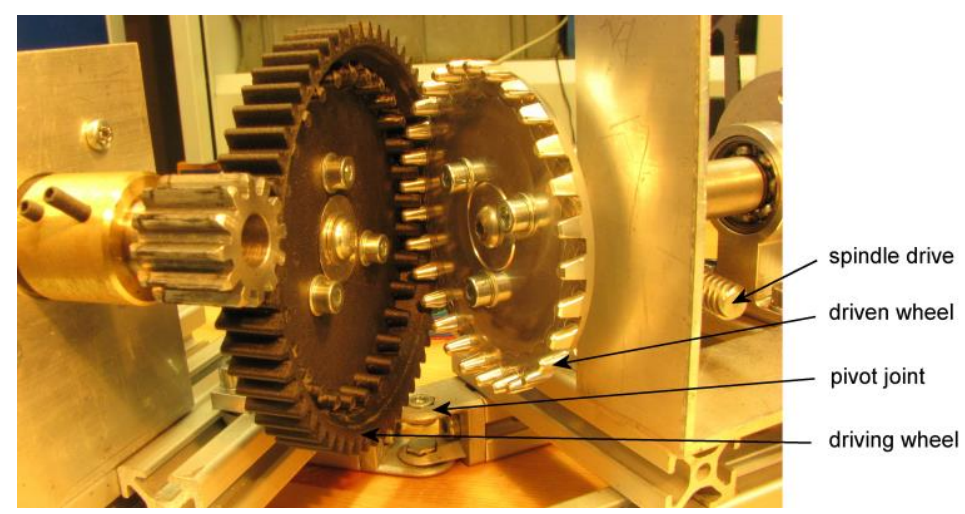

Figure 9. Test bench for validation of tooth system

The test bench was operated over 500 hours with $1 \mathrm{Nm}$ torque at $87 \mathrm{rpm}$ while changing direction of rotation and permanent variation of axis angle without any identifiable wear at the tooth flanks. The power is far from later real operating conditions of the omnidirectional treadmill but the target of the test was to show that the developed tooth profile works without any collision over the full range of axis angle.

\section{Summary and outlook}

Due to a parameter controlled virtual kinematic model the development of a tooth system for the special needs of an omnidirectional treadmill with variable shaft angle was possible. This is a modified crown gearing with barrel shaped teeth on driving wheel and cone shaped teeth on driven wheel. With optimized cone angles the collision of tooth mesh can be fully avoided for the claimed variation of shaft angle from $0^{\circ}$ to $60^{\circ}$. The applicability was also proven by a test bench.

In the next step a prototype of the omnidirectional treadmill will be built including this tooth system for driving the belt units. On this prototype more endurance tests will take place to verify the properties of the developed gearing system.

For further optimization of the tooth profile Nurbs spline curves (Piegl and Tiller, 1997) can be considered instead of the simple radius curved barrel shape. Weiss (2010) provides an advanced method for CAD-based spline structure optimization to generate automatically the spline geometry during an optimization run. The approach can also be interesting to be included into an automatic tooth profile generation from kinematic simulation.

\section{References}

Rudelstorfer, E. (2018), “Omnidirectional treadmill”, International patent application WO2018119485.

Basstein, G. and Sijtstra, A. (1993), "New developments in design, manufacturing and application of Cylkro(Face) gears", A.G.M.A. Technical paper, 93FTM7

Hayoz, C. (2015), CC BY-SA 4.0, https://commons. wikimedia.org/w/index.php?curid=39460687

Tsai, S.J. (1997), "Vereinheitlichtes System evolventischer Zahnräder - Auslegung von Zylindrischen", Konischen, Kronen- und Torusrädern, Dissertation TU Braunschweig 1997.

Roth, K. (1998), "Torusverzahnung für Achswinkeländerung während des Laufs", In: Karlheinz, R. (Ed.), Zahnradtechnik Evolventen-Sonderverzahnungen zur Getriebeverbesserung, Springer, Berlin Heidelberg, pp. 359-441. https://doi.org/10.1007/978-3-642-58890-7

Burkard, R.E. and Zimmermann, U.T. (2012), Einführung in die Mathematische Optimierung, Springer, Berlin Heidelberg 2012. https://doi.org/10.1007/978-3-642-28673-5

Philipp, M.H. (2014), Mathematisch-Technische Optimierung von Verzahnungsgeometrien, Disertation, Technische Universität München 2014

Seol, I.H. and Kim, D.H. (1998), "The kinematic and dynamic analysis of crowned spur gear drive", Computer Methods in Applied Mechanics and Engineering, Vol. 167 No. 1, pp. 109-118.

Li, H. et al. (2014), "The kinematic synthesis of involute spiral bevel gears and their tooth contact analysis", Mechanism and Machine Theory, Vol. 79, pp. 141-157.

Behnisch, S. (2003), Digital Mockup mit CATIA V5, Carl Hanser Verlag, München. ISBN 978-3-446-22379-0

Piegl L. and Tiller W. (1997), The nurbs book, Springer, Berlin. ISBN 978-3-540-61545-3

Weiss, D. (2010), "Feature-based spline optimization in CAD", Structural and Multidisciplinary Optimization, Vol. 42 No. 4, pp. 619-631. 